\title{
Preparation and Some Properties of Metal Organic Chemical Vapour Deposited Al-Doped ZnO Thin Films Using Single Solid Precursors
}

\author{
Olumide Oluwole Akinwunmi ${ }^{*}$, Johnson Ayodele O. Ogundeji ${ }^{1}$, \\ Adetokunbo Temitope Famojuro ${ }^{2}$, Olakunle A. Akinwumi ${ }^{1}$, Olusoji 0. Ilori ${ }^{3}$, \\ Olatomide G. Fadodun4, Ezekiel Oladele Bolarinwa Ajayi ${ }^{1}$ \\ ${ }^{1}$ Department of Physics and Engineering Physics, Obafemi Awolowo University, Ile-Ife, Nigeria \\ ${ }^{2}$ Department of Chemistry, Obafemi Awolowo University, Ile-Ife, Nigeria \\ ${ }^{3}$ Department of Electrical and Electronic, Obafemi Awolowo University, Ile-Ife, Nigeria \\ ${ }^{4}$ Centre for Energy Research and development, Obafemi Awolowo University, Ile-Ife, Nigeria \\ Email: *oakinwunmi@oauife.edu.ng, *ooakinwunmi@gmail.com
}

How to cite this paper: Akinwunmi, O.O., Ogundeji, J.A.O., Famojuro, A.T., Akinwumi, O.A., Ilori, O.O., Fadodun, O.G. and Ajayi, E.O.B. (2018) Preparation and Some Properties of Metal Organic Chemical Vapour Deposited Al-Doped ZnO Thin Films Using Single Solid Precursors. Journal of Modern Physics, 9, 2073-2089. https://doi.org/10.4236/jmp.2018.911130

Received: July 13, 2018

Accepted: September 25, 2018

Published: September 28, 2018

Copyright $(2018$ by authors and Scientific Research Publishing Inc. This work is licensed under the Creative Commons Attribution International License (CC BY 4.0).

http://creativecommons.org/licenses/by/4.0/

\begin{abstract}
Zinc Oxide ( $\mathrm{ZnO}$ ) and Aluminium doped $\mathrm{ZnO}(\mathrm{AZO})$ thin films were deposited on soda lime glass by Metal Organic Chemical Vapour deposition technique (MOCVD), using prepared compound mixtures of Zinc Acetate di-hydrate $\left(\mathrm{Zn}\left(\mathrm{CH}_{3} \mathrm{COO}\right)_{2} \cdot 2 \mathrm{H}_{2} \mathrm{O} ; \mathrm{ZAD}\right)$ and Aluminium Acetyl-Acetonate $\left(\mathrm{Al}\left(\mathrm{C}_{5} \mathrm{H}_{7} \mathrm{O}_{2}\right)_{3}\right.$; AAA) precursors at a temperature of $420^{\circ} \mathrm{C}$. Effects of the varying mole percent concentrations of AAA precursor additives on the Al dopant concentrations in $\mathrm{ZnO}$ were systematically studied. The observations were made via investigations carried out on the morphological, optical, electrical and compositional properties of the deposited thin films. The thin films morphology was found to be strongly dependent on the varying concentration of AAA in the precursor mixtures. The average optical transmittance of the thin films in the uv-visible region was over $85 \%$ except 5 mol.\% Al. While the energy band gaps were found to be in range of $3.27-3.36 \mathrm{eV}$. There is a blue-shift of the energy band edge observed between 0 and 5 mol.\% AAA, which may be due to Burstein-Moss' band gap widening effect and an opposing band gap renormalization effect at 10 mol.\% AAA along with an extra band gap stabilization effect (Roth's effect) at $15 \mathrm{~mol} \%$ AAA in rather quasi-sinusoidal or anomalous behaviour. The optical transmittance and electrical conductivity of $\mathrm{ZnO}$ were enhanced with addition of $\mathrm{Al}$ dopants. The RBS confirm the presence of $\mathrm{Al}, \mathrm{Zn}$ and $\mathrm{O}$, and evidence that $\mathrm{Al}$ dopants were successfully incorporated into the $\mathrm{ZnO}$.
\end{abstract}




\section{Keywords}

ZnO Thin Film, ZnO:Al, MOCVD, Optical Properties, AAA, ZAD, Electrical Properties, FESEM, UV-Vis, Optoelectronic Properties

\section{Introduction}

Within the present decade, the rate of development of optoelectronic materials applications has rapidly increased, with current research in transparent conducting oxides (TCO's) being directed towards choice materials capable of combining economical and environmentally sustainable superior performance. TCO's are generally classified as materials with combined high average optical transparency $>80 \%$, high electrical conductivity, and low resistivity of $\leq 1 \times 10^{-3} \Omega \mathrm{cm}$. The currently ubiquitous optoelectronic devices such as thin film solar cells, light emitting diodes (LEDs), transparent thin film transistors, piezoelectric transducers, gas sensors, flat and touch panel displays [1] [2] [3] laud TCO materials as the focal point for the interests of numerous research groups seeking to explore, enhance, optimize, stabilize and economize superior TCO materials performance in the nearest future. AZO thin films have superior advantages when compared with known TCO $\left(\operatorname{In}_{2} \mathrm{O}_{3}: \mathrm{Sn}\right.$ ITO $)$ in that $\mathrm{ZnO}$ is abundant in the earth crust when compared to Indium (In), eco-friendly, has high thermal, chemical and radiation stability in hydrogen plasmas and other harsh environments [4]. Moreover, there is a general ongoing trend in the TCO industry to move towards alternative solutions for more advanced applications [5]. In the recent time, AZO thin films were been deposited on flexible substrates and are attracting both research and technology's attention [6] [7].

TCOs' are majorly compound semiconductors, generally classified as either $\mathrm{n}$-type or p-type in line with their electrical properties. Their classifications are further subdivided into binary, ternary, quaternary compound and doped types. Doping $\mathrm{ZnO}$ with Group III elements ( $\mathrm{Al}$, In and $\mathrm{Ga}$ ) drastically enhances the electrical conductivity [8] [9] [10] [11]. TCO's have been fabricated by various methods, ranging from physical methods to chemical methods [5] [12] [13]. Metal organic chemical vapour deposition (MOCVD), which is a variant of Chemical method is an attractive technique for the fabrication of TCO's. This is due to its large-area to volume and conformal deposition capability even with less sophisticated apparatus, as well as close to ambient temperature deposition in contrast to PVD techniques. This paper is a report of MOCVD AZO thin films deposited on soda lime glass substrate, using single solid source precursors and the trends observed in its properties with varying $\mathrm{Al}$ dopant concentration. The prepared precursors were characterized using Fourier Transform Infrared (FTIR) spectroscopy while the thin films' properties were characterized using Field Emission Scanning Electron Microscopy (FE-SEM), Ultraviolet-Visible (UV-Vis) Spectroscopy, Four Point Probe technique and Rutherford Backscat- 
tering Spectroscopy (RBS).

\section{Experimental Details}

$\mathrm{ZnO}$ and AZO thin films were prepared by MOCVD technique. A schematic of the experimental set-up is shown in Figure 1(a). $0.03 \mathrm{M}$ starting solution was prepared from analytic grade ZAD (Fisher Scientific, UK; 99.999\%) and dissolved in methanol (BDH Analytical Chemicals, UK; 95.9999\% dilute). Varying concentrations of AAA (BDH Analytical Chemicals, UK; 99.999\%) previously dissolved in methanol at $0.03 \mathrm{M}$ was added to the prepared ZAD solution in

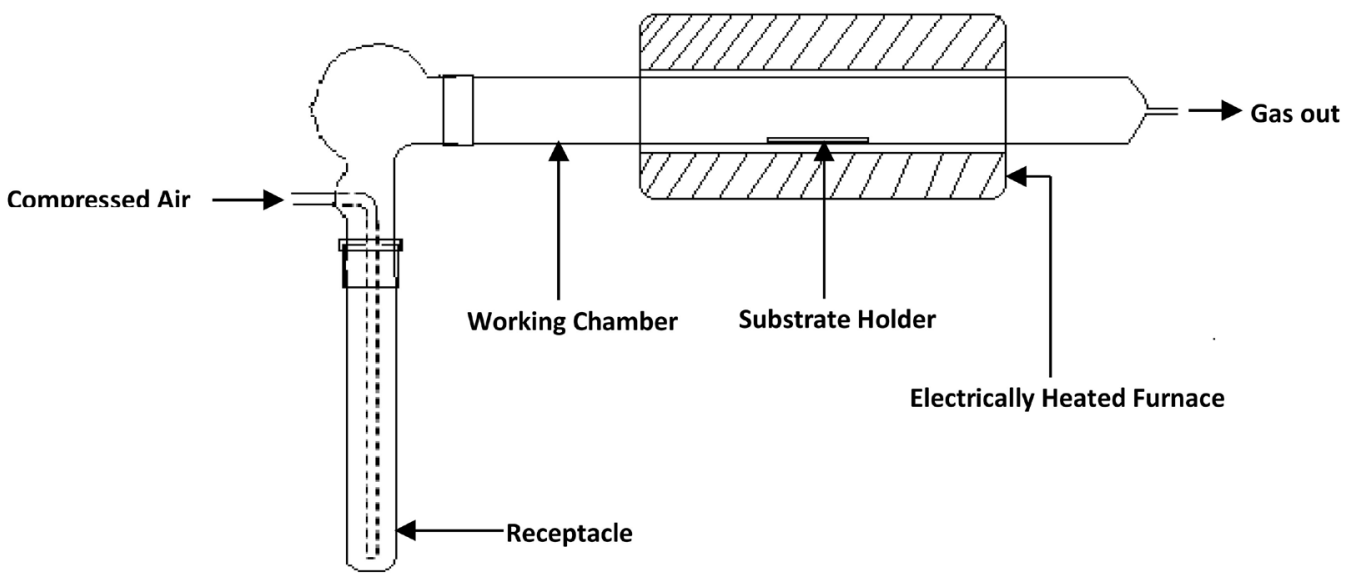

(a)

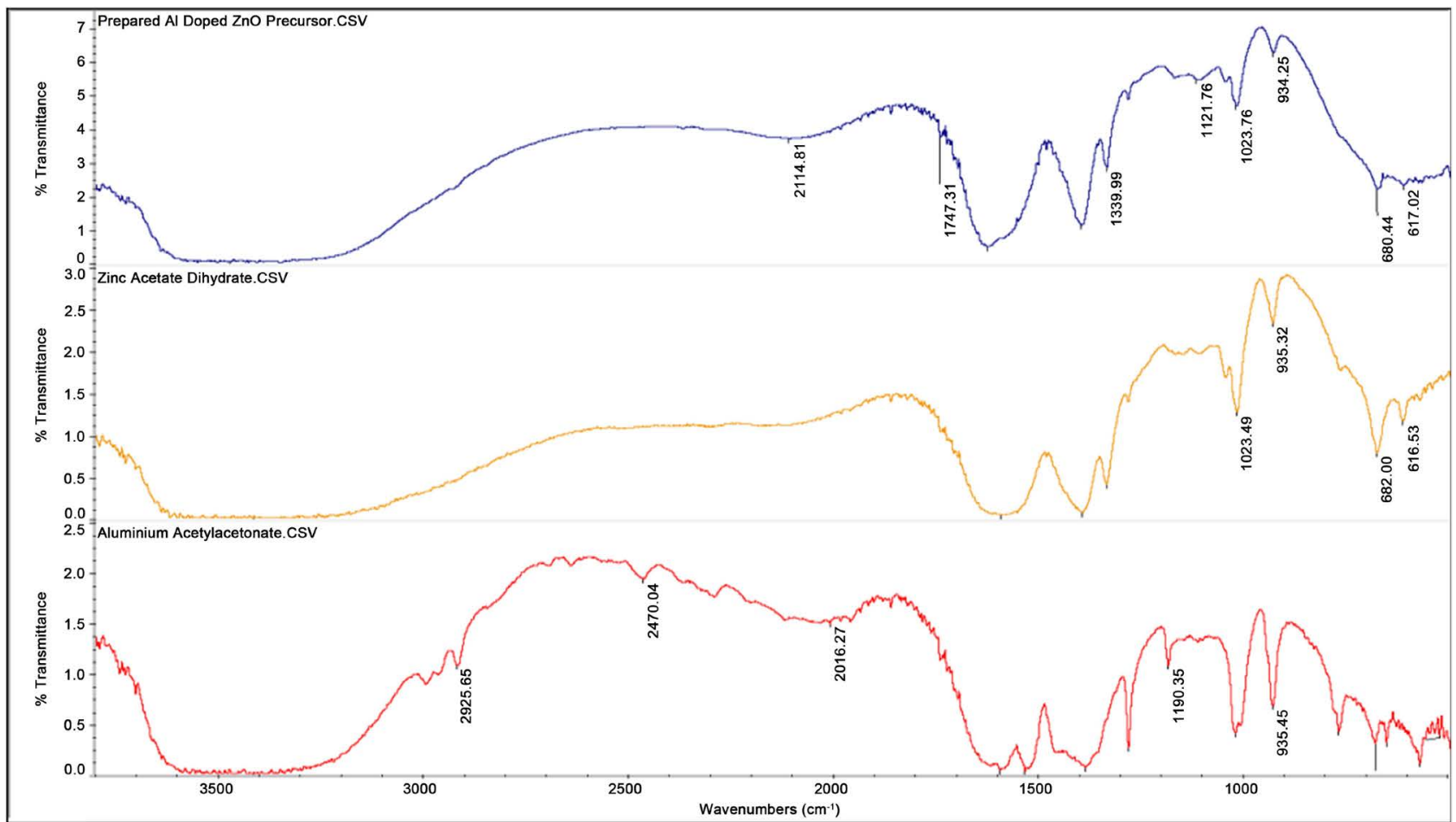

(b)

Figure 1. (a) A schematic of the experimental set-up; (b) FTIR spectra of the final single solid source precursor used and the starting solid materials ZAD and AAA. 
other to doped the initial solution such that the mole ratios of the precursors would be 95:5, 90:10 and 85:15 mol.\% respectively. The prepared solutions were oven dried to constant weight at $60^{\circ} \mathrm{C}$ for 48 hours. The resulting caked solids were pulverized just before the pyrolysis. The thin films were deposited onto cleaned soda lime glass substrates at $420^{\circ} \mathrm{C}$ for 2 hours using nitrogen as carrier gas with flow rate $2.5 \mathrm{dm}^{3} /$ min (Figure 1). The FTIR Spectrum of the individual and prepared precursor were taken using a Nicolat iS5 Spectrometer. The FE-SEM micrographs of the AZO thin films were obtained using a Zeiss plus 55 FE-SEM. Transmittance spectra were measured with Shimadzu UV-Vis 1800 double beam spectrophotometer in the wavelength range $280-800 \mathrm{~nm}$. The current-voltage (I-V) characteristics were studied within voltage sweep $0-0.5 \mathrm{~V}$, and carried out under normal conditions at room temperature using the four point probe technique, a Jandel four point probe tool (model TY242MP), and a Keithly 2636A dual channel source/measurement equipment unit all sealed in a dark room.

RBS Spectrum of the thin films were taken using a National Electrostatic Corporation's (NEC) 1.7 MV Tandem Accelerator with $2.202 \mathrm{MeV} \mathrm{He}^{++}$(mass = 4) nuclides as the ion beam. The beam incidence angle was $0.00^{\circ}$; the RBS detector was placed at a $168^{\circ}$ scattering angle and an exit angle of $12^{\circ}$. The depth profile of the thin films and their elemental compositions were obtained from the RBS spectrum using the SIMNRA and RUMP simulation software.

\section{Results and Discussion}

A pyrolytic process is known to occur close to a heated glass substrate when aerosol droplets in a jet or cloud arrive at the substrate, so that a highly adherent thin films of $\mathrm{ZnO}$ and $\mathrm{AZO}$ were formed on the substrate.

\subsection{Precursor Mixture Composition}

FTIR spectrum of the final single solid source precursor used and the starting solid materials AAA and ZAD were shown in Figure 1(b). As observed in the figure, AAA had undergone unintentional hydration. This can be interpreted in terms of the hydration of the complex in water. The distribution constants of metal acetylacetonates, between water and $\mathrm{n}-\mathrm{C}_{7} \mathrm{H}_{35}$ determined as a function of temperature have been reported to be most thermodynamically favourable than that of other trivalent acetylacetonates such as $\mathrm{Co}, \mathrm{Cr}, \mathrm{Rh}$. The higher hydration of AAA supports the idea that the hydration took place through the octahedral faces in the laboratory atmosphere before the precursor preparation [14]. Hence, the FTIR spectra show a strong intensity of the broad-peaked $\mathrm{O}-\mathrm{H}$ stiff bonds in a stretching mode at a higher vibrational frequency of between 3300 and 3500 $\mathrm{cm}^{-1}$. The broad peak observed in the ZAD between the same frequencies represents the hydration present in its molecular formula. On the other hand, the final product precursor formed; contain the $\mathrm{O}-\mathrm{H}$ broad peak contribution from the hydration of the AAA and ZAD precursor. The fingerprint region of each of the 
precursors is approximately below $1500 \mathrm{~cm}^{-1}$. Although, IR vibrations in this region are often complex and difficult to assign to a specific functional group of the molecule, the AAA, ZAD and final solid source product each have a distinct pattern in the region as can be observed by inspection. The ZAD spectrum is very similar to the solid source product than the AAA, since the number of possible vibrations for any given molecule is determined by the number of atoms present and hence the intensity of the peak observed. All the peaks in the fingerprint region of the solid source product align peak for peak with the ZAD with very minimal shifting or conjugation, except for the reductions in peak intensity of the solid source product precursor. $\mathrm{SP}^{3}$ hybridized $\mathrm{C}-\mathrm{H}$ bonds are observed in the AAA only between 2800 and $3000 \mathrm{~cm}^{-1}$. The $\delta \mathrm{C}-\mathrm{H}$ bond peaks are observed in all the precursors between 1293 and $1464 \mathrm{~cm}^{-1}$, as well as the $v \mathrm{C}=\mathrm{O}$ bond at $1596 \mathrm{~cm}^{-1}$. While the $v \mathrm{C}=\mathrm{O}$ bond connected to $\mathrm{Al}$ in AAA is at $1532 \mathrm{~cm}^{-1}$, its presence in the solid source product is observed as the left-skewed broad peak in the solid source product which is symmetrical in the ZAD. Also, the $v \mathrm{Al}=\mathrm{O}$ in $\mathrm{AAA}$ and $v \mathrm{Zn}=\mathrm{O}$ in $\mathrm{ZAD}$ spectra are observed at the same frequency, but diminished intensity in the solid source product between 1023 and $1026 \mathrm{~cm}^{-1}$ respectively, and suggesting a conjugation of the bonds between $\mathrm{Al}, \mathrm{Zn}$ and $\mathrm{O}$, as a result of the lowering of the stretching frequency resonance as observed at the peaks.

\subsection{Surface Morphology}

\section{Field Emission Scanning Electron Microscopy (FE-SEM)}

Figures 2(a)-(d) show the FE-SEM micrographs of as-deposited AZO thin films with ratio $0,5,10,15 \mathrm{~mol} \%$ of $\mathrm{Al}$ dopant. The micrographs show a strong dependence of the AZO thin films morphology on increasing aluminium concentration. As observed, a uniform, continuous and pin hole free morphology is shown in Figure 2(b) at 5 mol.\% Al dopant concentration implying the presence of low internal stress. The micrograph of as-deposited $10 \mathrm{~mol} \% \mathrm{AZO}$ in Figure 2 (c), show a uniformly granular polycrystalline morphology having almost the same sizes, with well-defined grain boundaries and an inhomogeneous surface with polygon-like grains that may efficiently scatter incident photons. The as-deposited $15 \mathrm{~mol} \% \mathrm{AZO}$ is polycrystalline with grains and obvious grain boundaries. This observation may be as a result of the an $\mathrm{Al}$ rich thin film, resulting in a degenerately doped layer of AZO and hence creating a highly distinct segregation of grains with possible accumulation of excess $\mathrm{Al}$ ions at the grain boundaries thus preventing further enlargement of the grains and grain boundaries. $\mathrm{Al}^{3+}$ as dopant substitute $\mathrm{Zn}^{2+}$ in $\mathrm{AZO}$ thereby increasing the nucleation site number [13]. In a degenerately doped $\mathrm{ZnO}$, there is a tendency for heavy and localized nucleation of grains to occur, such as observed in Figure 2(d).

\subsection{Optical Properties}

The effect of the increasing aluminium dopant concentrations on the optical 


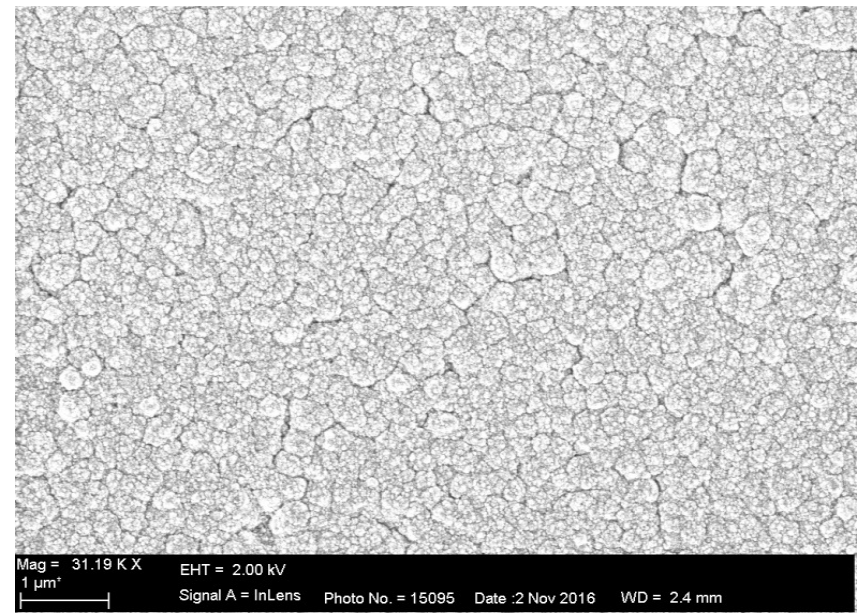

(a)

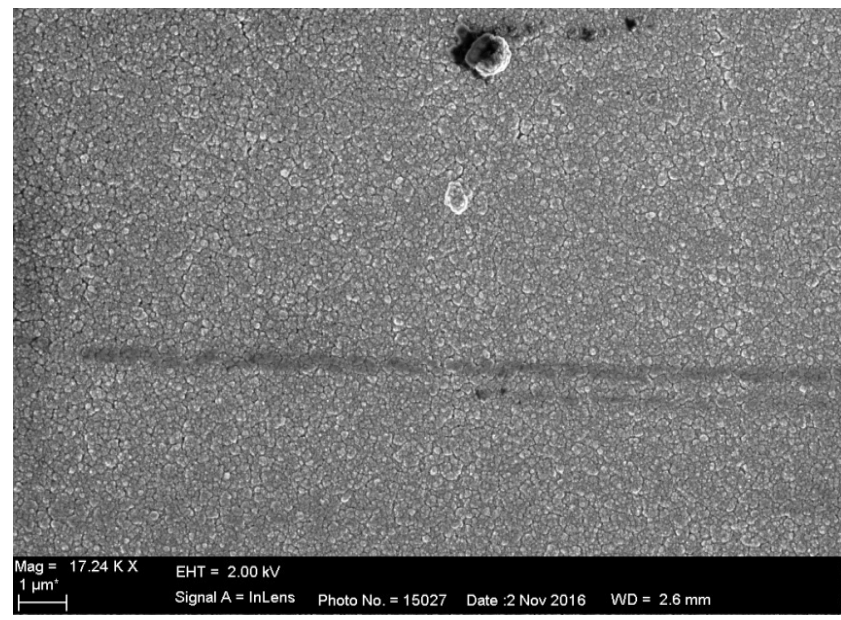

(c)

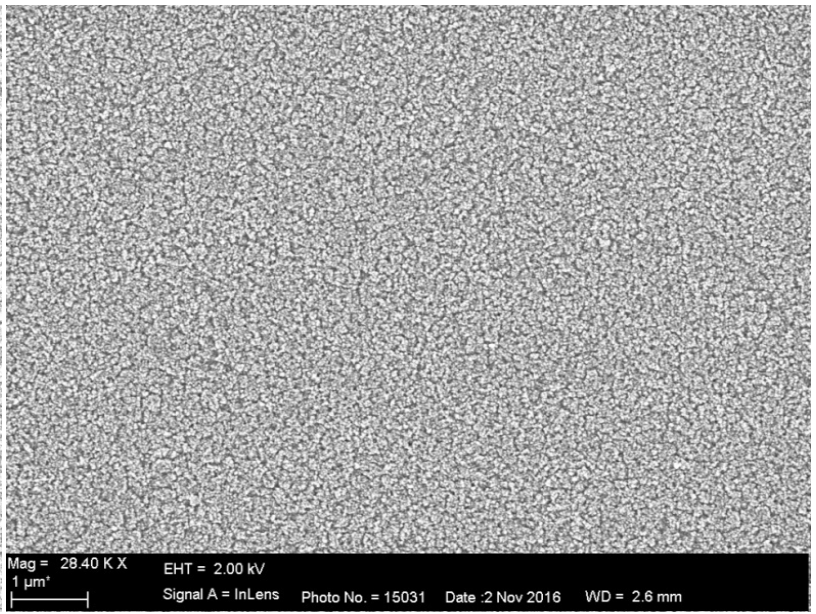

(b)

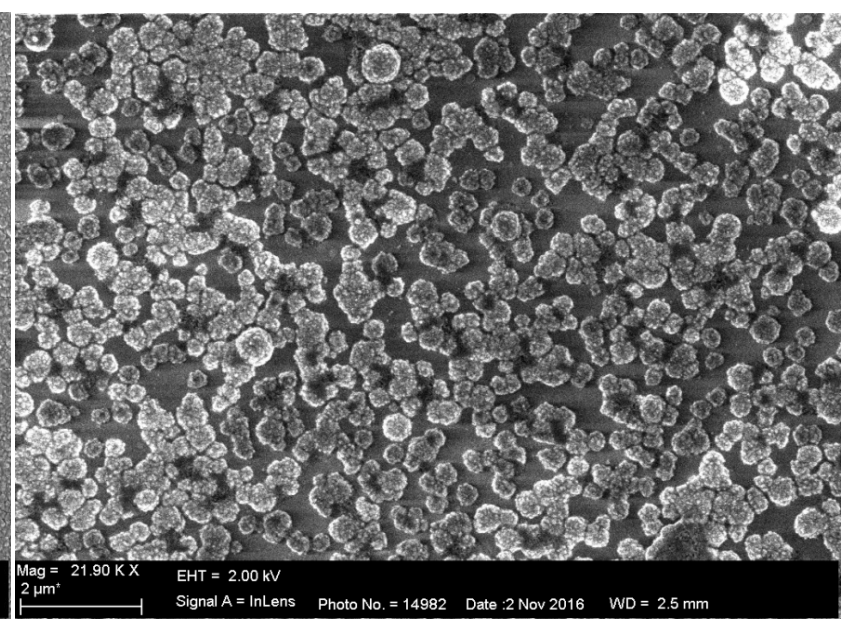

(d)

Figure 2. (a) FE-SEM image of AZO thin films (0 mol.\% Al); (b) FE-SEM image of AZO thin films (5 mol.\% Al); (c) FE-SEM image of AZO thin films (10 mol.\% Al); (d) FE-SEM image of AZO thin films (15 mol.\% Al).

transmittance of the AZO thin films are shown in Figure 3(a) \& Figure 3(b). The average transmittance in the near ultra-violet, visible and near infra-red region (380 to $800 \mathrm{~nm}$ ) combined is over $85 \%$ except $5 \mathrm{~mol} \% \mathrm{Al}$. The heavily doped AZO thin films show increase in average transmittance up to $91 \%$ within the wavelenght region studied, while undoped $\mathrm{ZnO}$ thin films was found to be $86 \%$. The 5 mol.\% AZO thin film's low transmittance appears to be as a result of excessive scattering centres in the amorphous structure of the thin film. Compressed air and nitrogen gas were each used as carrier gas to deposit the thin films at $10 \mathrm{~mol} \% \mathrm{Al}$ dopant concentration, and both gave an average transmittance of $92 \%$ within the same wavelength range. The transmittance of $\mathrm{ZnO}$ is greatly enhanced when the $\mathrm{Al}$ dopant concentration is greater than $10 \mathrm{~mol} \%$. In general the transmittance of the deposited film improves from $5 \mathrm{~mol} \% \mathrm{Al}$ dopant concentration in the presence of sufficient oxygen [10].

Other optical parameters of the AZO thin films such as the refractive index (Figure 3(c)) decreases with increase in transmittance. The observed opposite 


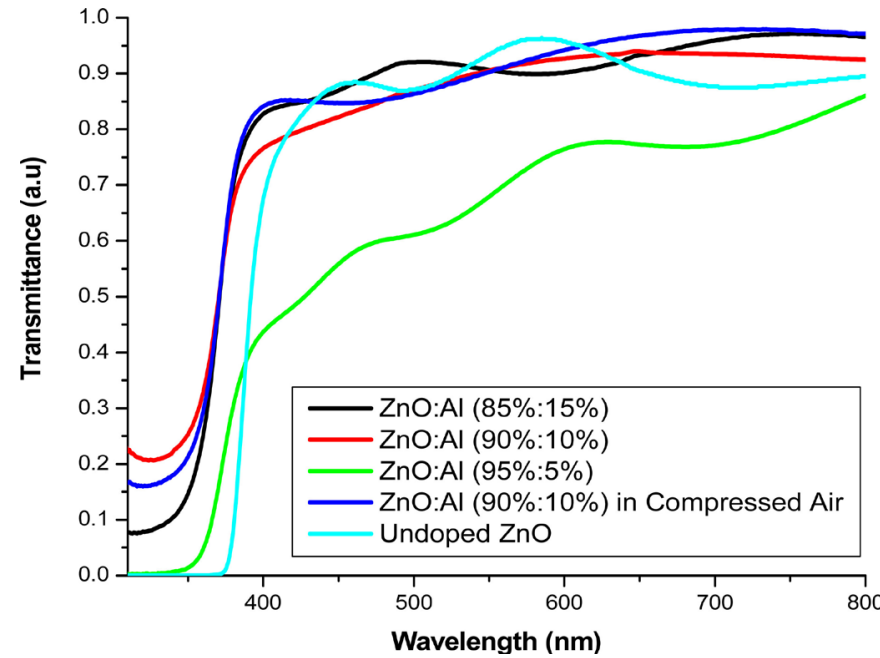

(a)

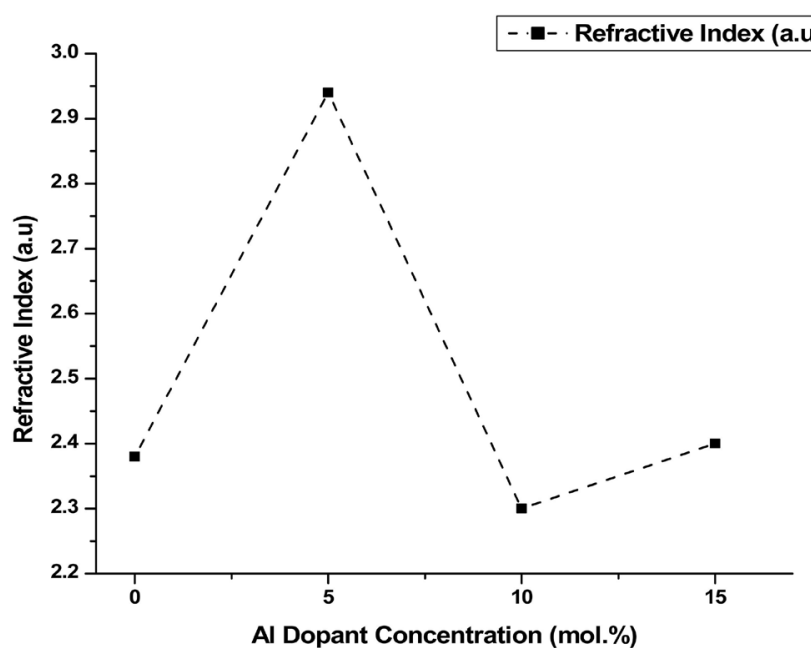

(c)

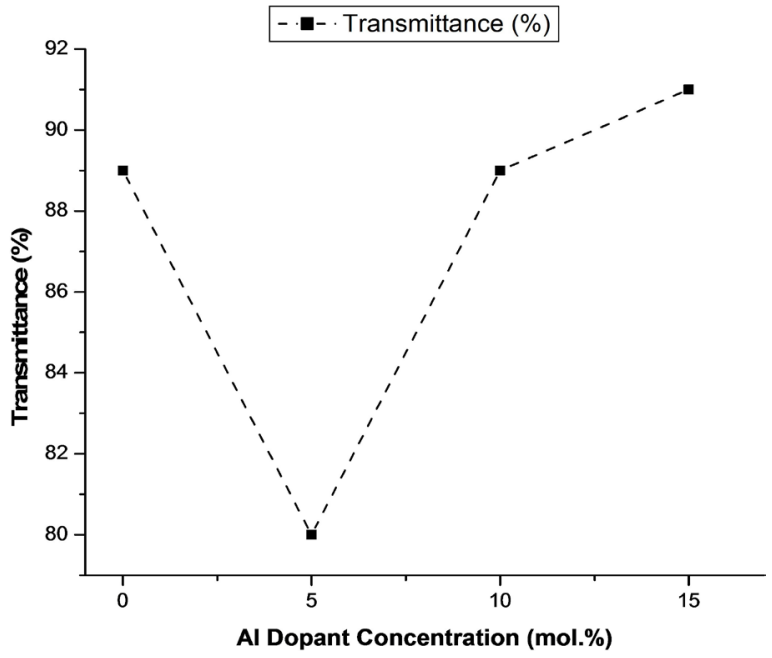

(b)

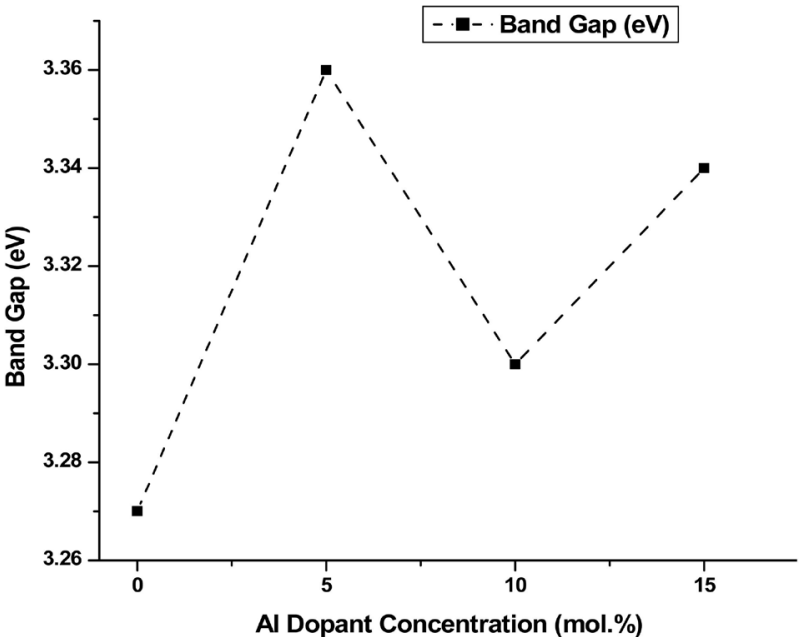

(d)

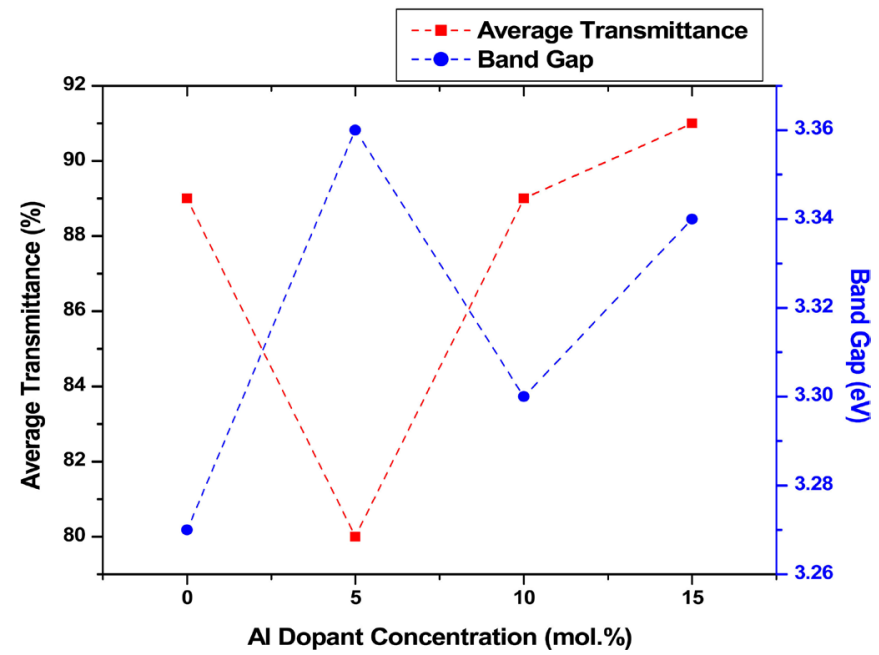

(e)

Figure 3. (a) Optical transmittance of the AZO thin films; (b) Average transmittance vs Al dopant concentration; (c) Refractive index ( $\mathrm{n}_{\text {thin film }}$ ) vs Al dopant concentration; (d) Energy band gap vs Al dopant concentration; (e) Average transmittance, band gap vs $\mathrm{Al}$ dopant concentration. 
trend of the refractive index is known to be as a result of the change in the nature of the microstructure arising from the changes in grain sizes with increasing $\mathrm{Al}$ dopant concentration [15] [16]. In fact, the inhomogeneity of the grains resulted in the lower average transmittance in the 5 mol.\% AZO thin film, creating uneven scattering centres and hence an abruptly increased refractive index. The band-gaps on the other hand, are observed to have all blue-shifted in $\mathrm{ZnO}$ with increasing $\mathrm{Al}$ dopant concentration as shown in Figure 3(d). The blue-shift of the absorption edge may be due to the increase in carrier concentration as a result of the increase in the $\mathrm{Al}$ dopant concentration. The blue-shift is intricately related to the screening effect which occurs as low energy transitions are blocked, resulting in a Burstein-Moss band-gap widening effect [16] [17] [18]. The parabolic structure of the conduction band observed as an abrupt near zero tailing off of the absorption edge in undoped $\mathrm{ZnO}$ (Figure 3(a)) infers the theoretical absence of defects due to impurities in its structure. However, an exponential structure of the conduction band results as observed at the gradual tailing off of the absorption edges in the AZO thin films (Figure 3(a)), hence identifying deep band defect states due to $\mathrm{Al}$ dopants propagated as far as the absorption edges. Tail states created at the absorption edges are not terminated abruptly, but extend gradually from the near absorption band into the absorption band edges. The Tauc's equation was therefore used to evaluate the band gaps for the doped AZO thin films, since it gives a better estimate, taking into consideration the contributions of such deep band defect states as well as tail states near the absorption edges [19]. The energy band gap values of each AZO thin film was evaluated from $(\alpha h v)^{2}$ as a function of $(h v)$ in the Tauc's equation

$$
(\alpha h v)^{2}=A\left(h v-E_{g}\right)
$$

where $\alpha$ is the absorption coefficient, $h v$ is the photon energy, $A$ is a constant that depend on the material's properties, and $E_{\mathrm{g}}$ is the optical band gap energy respectively. The plot for undoped $\mathrm{ZnO}$ when extrapolated from the linear region of the square of the absorption coefficient tail to the point where $(\alpha h v)^{2}=0$, intercepted the abscissa at the energy band gap value $3.27 \mathrm{eV}$. However, in direct gap semiconductors such as $\mathrm{ZnO}$, disorder due to impurity and temperature effects will cause the exponential band tails of the electronic states to extend into the semiconductors forbidden gap. This causes optical transitions to occur near the absorption edge such that the transitions manifest an exponentially varying absorption coefficient $(\alpha)$ as the electrons move from a parabolic band to an exponential band-tail state.

The sharp widening of the band gap of $\mathrm{ZnO}$ at $\mathrm{Al}$ dopant concentration of 5 mol.\% may be due to Burstein-Moss effect. And the subsequent contraction 10 mol.\% may be attributed to band-gap renormalization, followed by the phenomenon of an additional stabilization deposition temperature based effect known to occur in an inert gas atmosphere such as $\mathrm{N}_{2}(\mathrm{~g})$ at $420^{\circ} \mathrm{C}$ (Roth's effect) at 15 mol.\%. This effect acts as an opposing force to the Burstein-Moss band gap widening effect and tries to restore or renormalize the band gap to its initial value 
following a heavy dopant concentration [20]. These effects are typical of the optical band gap of nanocrystalline $\mathrm{ZnO}$ thin films. According to Srikant and Clarke, the Burstein-Moss effect is valid for materials having low effective mass of electrons and holes. That is, materials in which quantum confinement lead to an initial rise in the optical band gap [21]. This appears contradictory with the results of this study, in which the AZO thin films are not only degenerately n-type doped, but thicknesses are way more than that permissible in quantum confinement studies. Yet, an initial band gap widening offset partially by a band-gap renormalization was observed. However, recent studies through density-functional band-structure theory demonstrate that the band-gap renormalization is related to the non-parabolic nature of the host conduction band $(\mathrm{ZnO})$, created as a result of the dopant impurities, and not because of a rigid shift of the band edges as studies have earlier assumed [22]. As a result, the carrier dependence of the Burstein-Moss' band-gap widening in this study is rather highly sensitive to the electronic states of the dopant ion $\left(\mathrm{Al}^{3+}\right)$ which in turn can be intrinsically involved in the complete reconstruction of the conduction band, thus lowering it. This effect is better observed in Figure 3(e), the band-gap widening from 0 to 5 mol.\% $\mathrm{Al}$ dopant concentration is as a result of the occupation of the AZO conduction band, inducing optical transitions at higher energies than the minimum-energy of the fundamental electronic gap (undoped $\mathrm{ZnO}$ ). Meanwhile, and on the other hand, increase in free carrier screening will result in the decrease in the binding energy of the optical transitions associated with both free and bound excitons. So that, in the undoped $\mathrm{ZnO}$ and the AZO thin films, both the free and bound exciton transitions show a quasi-sinusoidal blue-shift and red-shift as the exciting wavelength of the UV-Visible radiation is decreased and intensity maintained with increasing dopant concentration [23]. The renormalization effect results in a red-shift of the optical transitions, and therefore a reduced free-carrier screening effect of photons resulting in increased average transmittance as a result of the reduction in the band-gap energy. The energies of the optical transitions are therefore the resultants of the blue-shift due to screening, and the red-shift due to the renormalization effect. The entire energy interplay weakens as the dopant concentration increases (up to15 mol.\%), so that a stability effect (Roth's effect) converges both the average transmittance and the band-gap to a stable value. The energy positions are determinable by the aggregated effects of screening and band-gap renormalization resulting from the added free electrons. In this study the exact energy position was not determined but rather we try to establish the trend for the optical transition energies.

\subsection{Electrical Properties}

Linear current-voltage (I-V) characteristics are observed in the 5 and 10 mol.\% AZO thin films as shown in Figure 4(a) and Figure 4(b), while the non-linear I-V character of the 15 mol.\% AZO thin film in Figure 4(c) predict that there might be more than one mechanism of electron transport at play. The values of the sheet resistances of the AZO thin films were calculated from equation 


$$
R_{s}=\rho / t
$$

where $R_{s}$ is the sheet resistance in ohm/square, $\rho$ is the resistivity in ohm-cm and $t$ is the thickness of the thin film.

A decrease in the sheet resistances of the AZO thin films is observed for thickness ranges from 487 to $634 \mathrm{~nm}$. Therefore, a corresponding decrease in the resistivity is partly due to the presence of defects and majorly to Al dopants located as interstitial atoms and hence substitute $\mathrm{Zn}$, and filling Oxygen vacancies [24]. This may be due to the donor states created as a result of the $\mathrm{Al}^{3+}$ ions impurity introduced in the $\mathrm{ZnO}$ lattice structure, producing in all cases an n-type semiconductor [4]. The degree of corresponding increase in the conductivity realizable, given the aforementioned processing conditions of the AZO thin films in the as-deposited state is directly influenced by point defects such as oxygen vacancies acting as doubly charged electron donor centres, and structural defects due to the substitution of $\mathrm{Zn}$ atoms amidst other defects. Together with the $\mathrm{Al}^{3+}$ ions impurity increasingly introduced, this defects impact greatly on the carrier mobility within the AZO thin films. In addition, an increase in oxygen vacancies will increase the number of free electrons, which in turn increases the conductivity abruptly [13]. Al dopant concentration and oxygen vacancies creation most possibly resulted in the abrupt increase of the conductivity from 0 mol.\% to $5 \mathrm{~mol} . \%$. The interplay of increased $\mathrm{Al}^{3+}$ ion substitution of $\mathrm{Zn}$ atoms and oxygen vacancies more greatly modified the $10 \mathrm{~mol} \% \mathrm{Al}$ dopant concentration as observed in the value of the sheet resistances shown in the legends in Figures 4(a)-(c) respectively. The conductivity of 15 mol.\% AZO also increased, but was lower than that of 5 mol.\% AZO given the same processing conditions and comparable film thicknesses. Apparently, the heavily doped 15 mol.\% AZO thin film had the highest $\mathrm{Al}^{3+}$ ion impurity content, but as well the lowest number of oxygen vacancy which directly degrading the doping efficiency and compactness. At high $\mathrm{Al}$ dopant concentration, there is possibility that conduction by hopping mechanism will occur since the FE-SEM micrograph (Figure 2(d)) shows highly clustered and segregated grains across the AZO thin film [5] [13] [25].

TCO performance factor, energy band gaps, thickness and resistivity were shown in Figures 4(d)-(g). The interpretation of these trends with the FE-SEM images reveals the microstructural evolution of the AZO thin films. In Figure 4(d) the sheet resistance and average transmittance are observed to decrease with increase in dopant concentration from 0 to $5 \mathrm{~mol}$.\%. However, a lower sheet resistance in combination with a higher average transmittance is desirable for TCO material applications. On the other hand, while the average transmittance of the AZO thin films increased from $5 \mathrm{~mol} \%$ to $10 \mathrm{~mol} \%$ dopant concentration, the sheet resistance effectively decreased as well; an advantageous trend.

It is therefore pertinent to note that both parameters are correlated by an important figure of merit [26] [27], which measures TCO performance $\left(\Phi_{\mathrm{TC}}\right)$ as follows: 


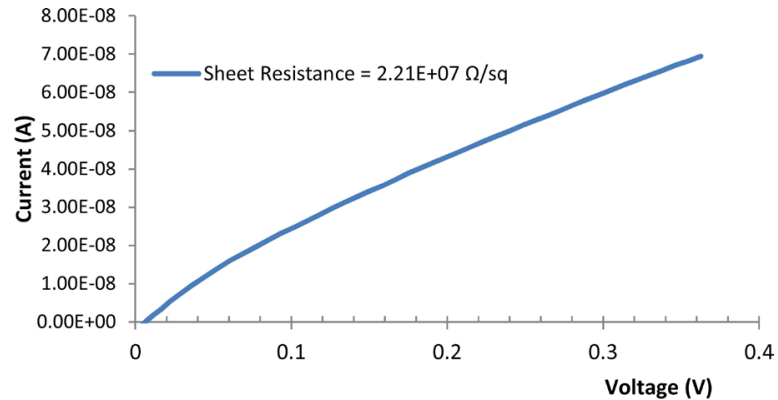

(a)

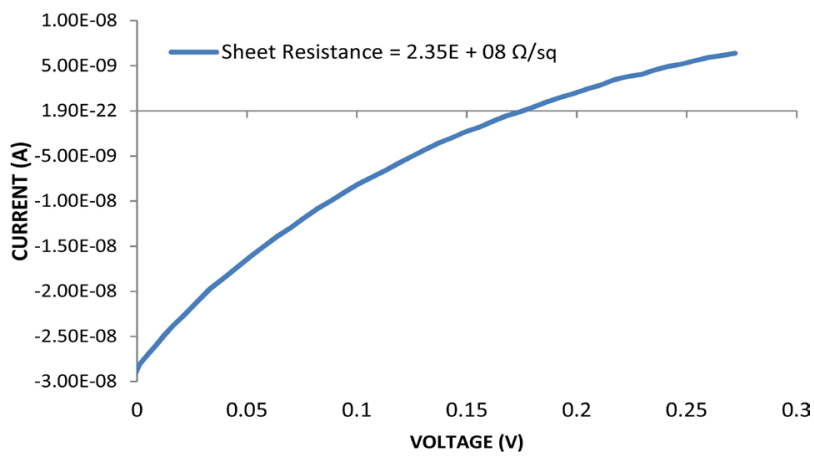

(c)

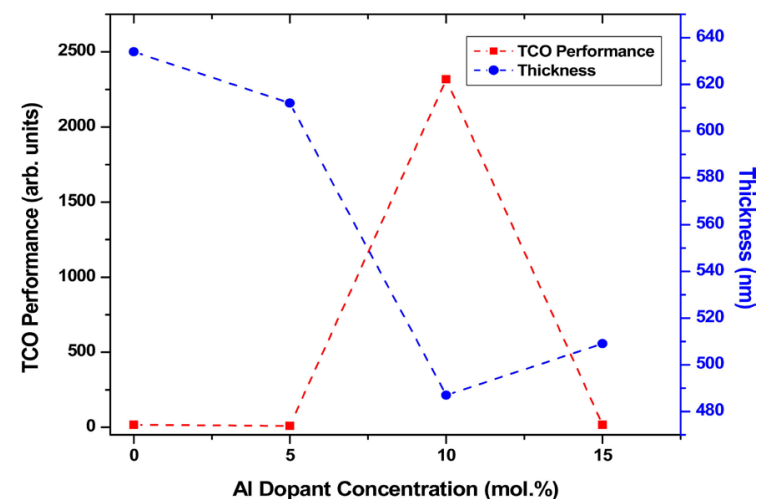

(e)

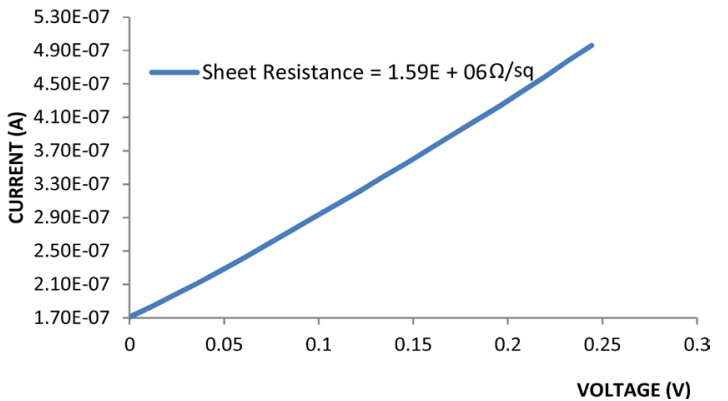

(b)

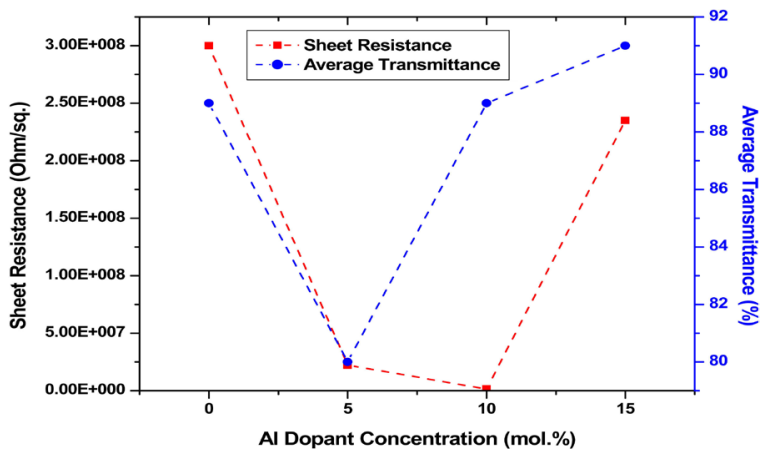

(d)

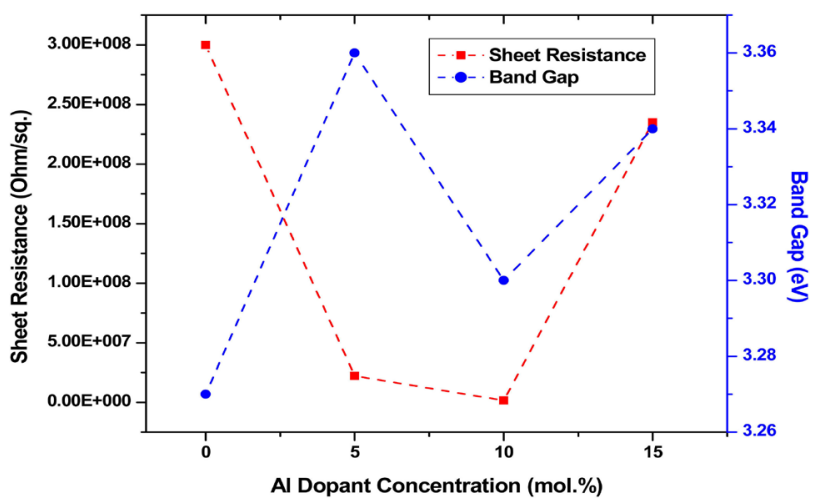

(f)

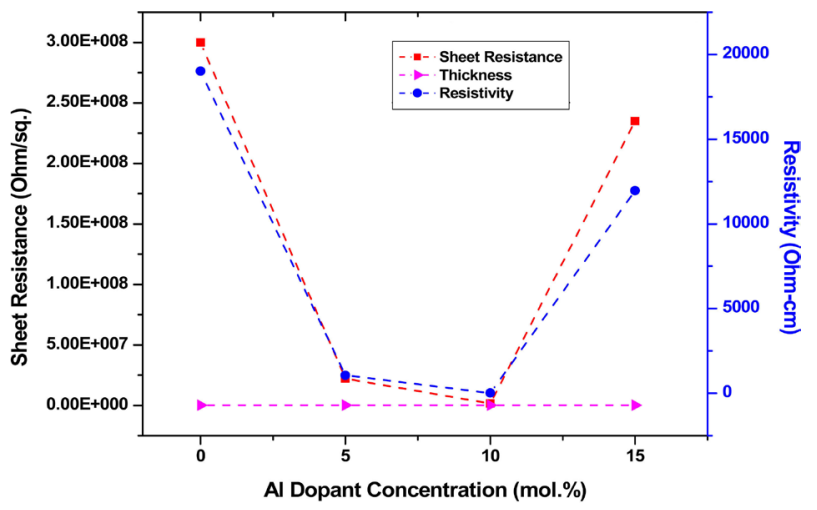

(g)

Figure 4. (a) Current vs voltage (ZnO:Al; 95:5); (b) Current vs voltage ( $\mathrm{ZnO}: \mathrm{Al} ; 90: 10)$; (c) Current vs voltage ( $\mathrm{ZnO}: \mathrm{Al}$; 85:15); (d) Sheet resistance, average transmittance vs Al dopant concentration; (e) TCO performance $\left(\Phi_{\mathrm{TC}}\right)$, thickness vs Al dopant concentration; (f) Sheet resistance, band gap vs Al dopant concentration; (g) Sheet resistance, resistivity and thickness vs Al dopant concentration. 


$$
\Phi_{T C}=\frac{T^{10}}{R_{s}}
$$

where $\mathrm{T}(\%)$ is the optical transmittance at a specified wavelenght $\lambda=550 \mathrm{~nm}$, and $\mathrm{R}_{\mathrm{s}}(\Omega / \mathrm{sq})$ is the sheet resistance. Figure $4(\mathrm{e})$ shows that $\Phi_{T C}$ values of the thin films decrease from 0 mol.\% to 5 mol.\% with a slight decrease of the thin film thickness from 634 to $612 \mathrm{~nm}$, but increase sharply beyond this range. The value of $\Phi_{T C}$ increased abruptly to a high level at $10 \mathrm{~mol} \%$ due to the low sheet resistance and the high transmission of the AZO layer combined with a decreased thickness of $487 \mathrm{~nm}$. $\Phi_{T C}$ decreased sharply below the $10 \mathrm{~mol} \%$ value to a value comparable to the $0 \mathrm{~mol} . \%$ value at $15 \mathrm{~mol} . \%$. This is due to a high sheet resistance, though with the same transmission as the $10 \mathrm{~mol} \% \mathrm{AZO}$ thin film, but at a higher thickness of $509 \mathrm{~nm}$. While Figure 4(f) shows an opposite trend with Figure $4(\mathrm{~d})$ in the sheet resistance values with the band gap, Figure $4(\mathrm{~g})$ shows a one to one correlation between the sheet resistance and resistivity giving an almost linear correlation in the values of the thickness as compared with the large magnitude of the sheet resistances.

\subsection{Composition and Depth Profile of AZO Thin Films}

RBS measurements were carried out in order to determine the composition of the undoped $\mathrm{ZnO}$ and $\mathrm{AZO}$ thin films deposited on soda lime glass substrates. Additional information regarding the depth profiles of the blank substrate, the undoped $\mathrm{ZnO}$ and the $\mathrm{AZO}$ thin films are given in Figures 5(a)-(c) respectively. The depth profile of all the deposited thin films confirmed the presence of $\mathrm{Zn}, \mathrm{O}$ and $\mathrm{Al}$ along with an estimated ratio of the film thickness.

Table 1 shows the RBS absolute data of the elemental concentrations of each constituent atom in the as-deposited AZO thin films with undoped $\mathrm{ZnO}$ as reference. The spectroscopically determined $\mathrm{Al}$ dopant concentration in atom percent measured in the as-deposited AZO thin films layers are observed to be strongly correlated with the $\mathrm{Al}$ dopant concentration experimentally calculated by weight in the prepared precursor as shown in the $\mathrm{Zn} / \mathrm{Al}$ ratios (Table 1) and were found to be close in value within approximate decimals for Al dopant concentrations in 10 and $15 \mathrm{~mol} \%$ AZO thin films. Major constituent of the soda lime glass substrate used in this study is silicon ( $\mathrm{Si}$ ) and oxygen $(\mathrm{O})$, with $\mathrm{O}$ having a concentration of 83.66 at.\% as observed in the RBS depth profile of the blank soda lime glass slide in Figure 5(a).

The depth profiles of 0 and 15 mol.\% AZO thin films were shown Figure 5(b) and Figure 5(c). This revealed almost constant elemental concentration of the $\mathrm{O}$ specie in all the as-deposited AZO thin film layers as contrasted with the reduced $\mathrm{O}$ concentration of 70.05 at.\% in the substrate layer. A reduction in the $\mathrm{O}$ specie concentration from 83.66 to 70.5 at.\% in the blank soda lime glass slide in all the AZO thin films substrates confirm an underlying process of the diffusion of $\mathrm{O}$ species from the substrates layers into the undoped $\mathrm{ZnO}$ and $\mathrm{AZO}$ thin films layers. This may be due to the deposition temperature and the elements to 


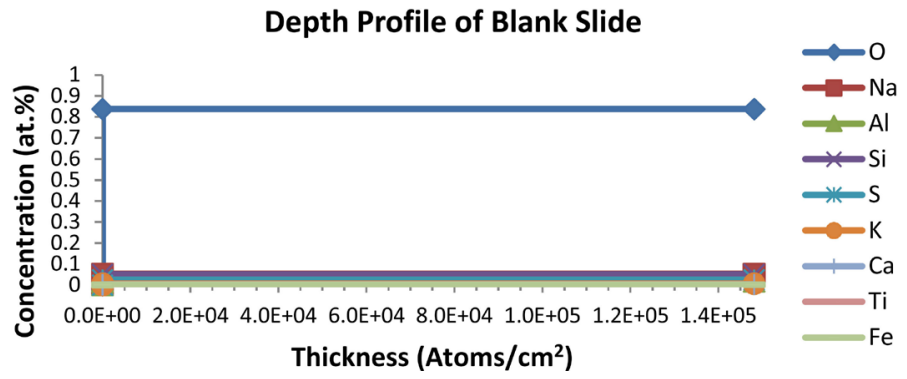

(a)

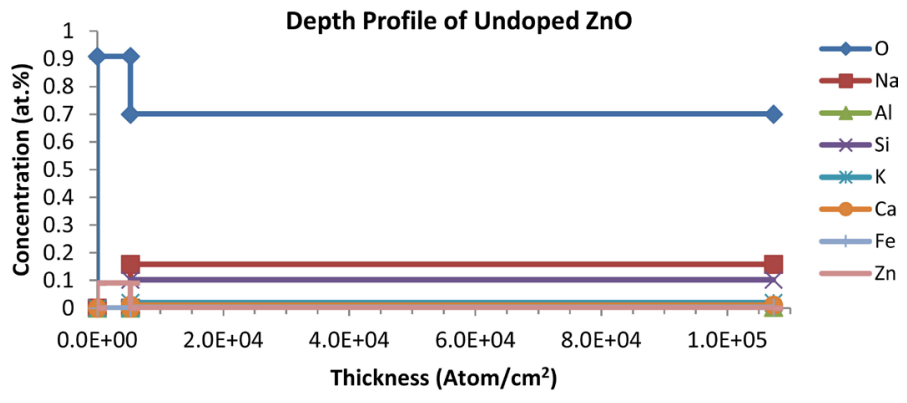

(b)

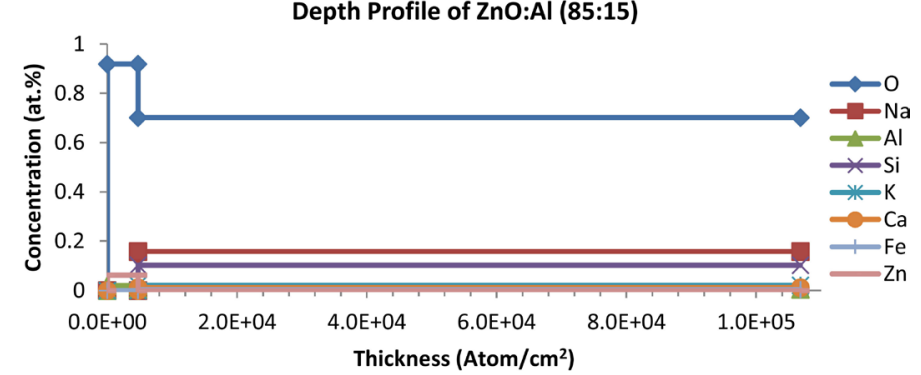

(c)

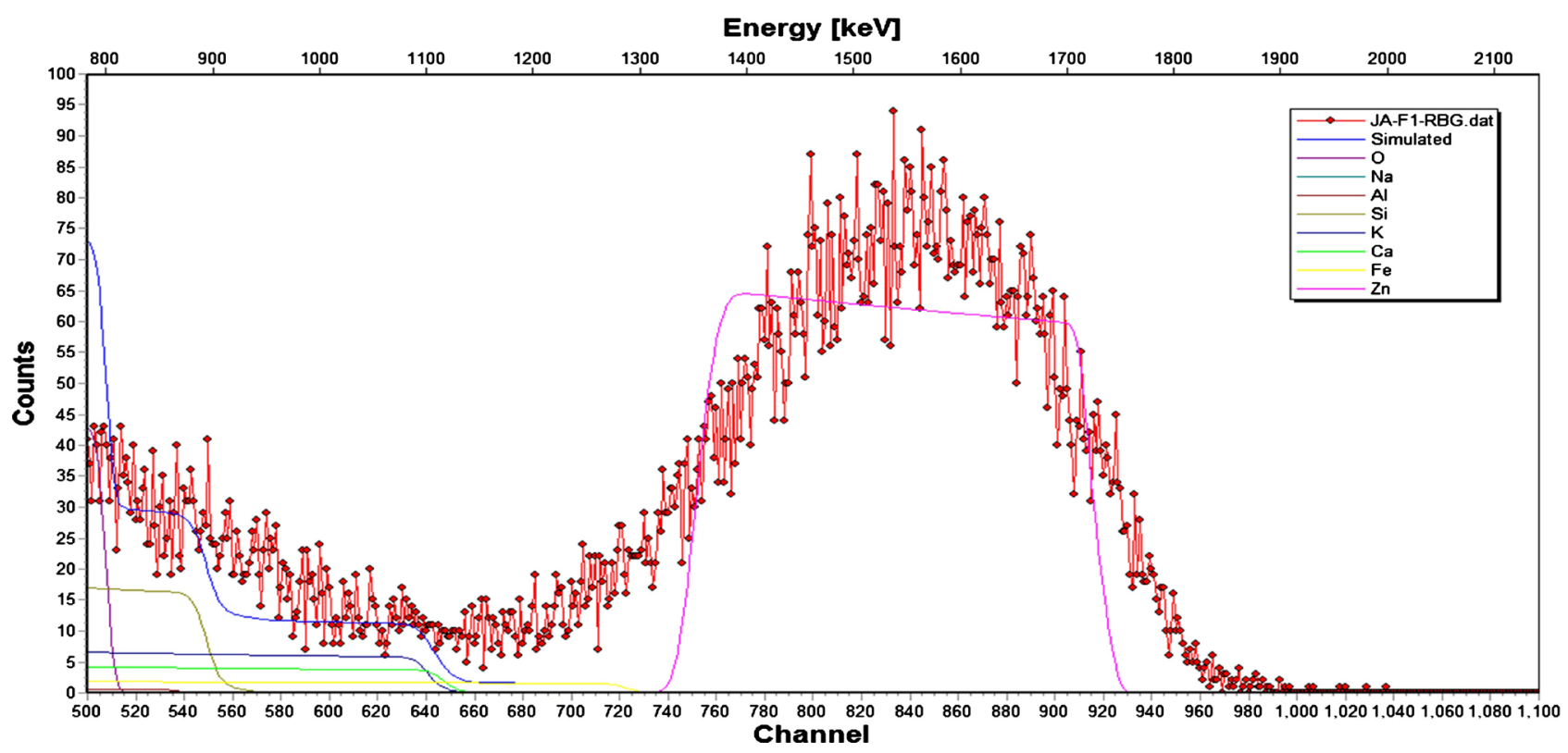

(d)

Figure 5. (a) Depth profile of blank slide substrate; (b) Depth profile of ZnO; (c) Depth profile of ZnO:Al (85:15); (d) RBS spectrum of AZO thin films on soda-lime glass substrate. 
Table 1. RBS data of the elemental concentrations of each constituent atom in AZO thin films.

\begin{tabular}{|c|c|c|c|c|c|c|}
\hline $\begin{array}{l}\text { Experimentally Measured } \\
\text { Ratio of Precursor } \\
\text { Mixtures in mol.\% (Zn } \\
\left.\text { Acetate: } \mathrm{Al}(\mathrm{Acac})_{3}\right)\end{array}$ & $\begin{array}{c}\text { Experimentally } \\
\text { Calculated } \mathrm{Zn} / \mathrm{Al} \\
\text { Ratio in Precursor } \\
\text { Mixtures }\end{array}$ & $\begin{array}{l}\text { RBS Elemental } \\
\text { Concentration of } \mathrm{Zn} \\
\text { (at.\%) in the Thin } \\
\text { Films }\end{array}$ & $\begin{array}{l}\text { RBS Elemental } \\
\text { Concentration of } \\
\text { O (at.\%) in the } \\
\text { Thin Films }\end{array}$ & $\begin{array}{l}\text { RBS Elemental } \\
\text { Concentration of } \\
\text { Al (at.\%) in the } \\
\text { Thin Film }\end{array}$ & $\begin{array}{l}\mathrm{Zn} / \mathrm{Al} \text { Ratio RBS } \\
\text { Elemental } \\
\text { Concentration in } \\
\text { the Thin Films }\end{array}$ & $\begin{array}{l}\text { RBS Determined } \\
\text { Thin Film } \\
\text { Thickness }\left(10^{15}\right. \\
\left.\text { Atoms } / \mathrm{cm}^{2}\right)\end{array}$ \\
\hline 100:0 (Undoped $\mathrm{ZnO})$ & - & 0.091136 & 0.908864 & - & - & $5230.50(634 \mathrm{~nm})$ \\
\hline $95: 5$ & 9.50 & 0.085263 & 0.902635 & 0.012102 & 7.05 & $5167.21(612 \mathrm{~nm})$ \\
\hline $90: 10$ & 4.50 & 0.073136 & 0.911772 & 0.015092 & 4.85 & $4488.07(487 \mathrm{~nm})$ \\
\hline $85: 15$ & 2.83 & 0.062243 & 0.918100 & 0.019657 & 3.17 & $4738.62(509 \mathrm{~nm})$ \\
\hline
\end{tabular}

which the $\mathrm{O}$ are bonded in the substrate. In addition, $\mathrm{O}$ impurities emanating from the substrate, and promoted by a high substrate temperature regime $\left(420^{\circ} \mathrm{C}\right)$ result in an out-diffusion effect, which compensate the donor character of the $\mathrm{Al}$ dopants in the AZO thin films [28]. This is evidence in observed highest sheet resistance obtained in the undoped $\mathrm{ZnO}$ layer with the highest $\mathrm{O}$ concentration in Figure 5(b), and the lowest sheet resistance with a comparably low $\mathrm{O}$ concentration in the $10 \mathrm{~mol} \% \mathrm{AZO}$. The $\mathrm{O}$ contribution from the precursor mixtures to the stoichiometry of undoped $\mathrm{ZnO}$ and the $\mathrm{AZO}$ thin films is therefore greatly masked by the diffused $O$ from the substrate layer. A direct deduction of the $\mathrm{O}$ contribution to the undoped $\mathrm{ZnO}$ and the $\mathrm{AZO}$ thin films from that of the soda lime glass substrate gives the stoichiometry expected from the precursor mixture. The relationship between the $\mathrm{Zn}$ and $\mathrm{Al}$ atomic content incorporated in the $\mathrm{AZO}$ thin films, as a function of $\mathrm{Zn}$ in the undoped $\mathrm{ZnO}$ were shown in Table 1. It is observed that the spectroscopically determined $\mathrm{Zn} / \mathrm{Al}$ ratio in all the AZO thin films decreased by an approximate constant factor of 2 , as the spectroscopically determined $\mathrm{Al}$ dopant concentration increased correspondingly with the experimentally calculated $\mathrm{Al}$ dopant concentration in the single solid precursors mixtures. This indicates that the $\mathrm{Al}$ dopants were successfully incorporated into the $\mathrm{ZnO}$ as each $\mathrm{Al}^{3+}$ cation substitutes $\mathrm{Zn}^{2+}$ cation in the lattice, and is attributed to the fact that the $\mathrm{Al}^{3+}$ is a most favorable $\mathrm{Zn}^{2+}$ substitute, because the ionic sizes of $\mathrm{Al}$ and $\mathrm{Zn}$ are closely matched; with $\mathrm{Al}^{3+}$ having the smaller ionic radius to easily substitute $\mathrm{Zn}^{2+}$. According to normal doping rules, $\mathrm{Al}^{3+}$ can occupy $\mathrm{Zn}^{2+}$ sites only up to its solubility limit of 0.3 at.\% in $\mathrm{ZnO}$. Else, beyond the solubility limit, new phases of $\mathrm{Al}_{2} \mathrm{O}_{3}$ arise so that the substitution of $\mathrm{Al}$ is no longer as effective [29]. The study therefore shows $\mathrm{Al}^{3+}$ solubility factor of 15 below the solubility limit, implying the possibility of further incorporation of $\mathrm{Al}^{3+}$ in the $\mathrm{ZnO}$ lattice given the advantages of the favorable process conditions used. The RBS spectrum in Figure 5(d) shows the degree of the AZO thin film layer uniformity for the $15 \mathrm{~mol} \% \mathrm{Al}$ dopant concentration and its corresponding simulated spectrum against the substrate background. Of particular interest also in this study from the figure is that the boundary layer between the substrate layer and thin film layer interface is not well defined. The thickness of the boundary layer is a function of the diffusion coefficient of the individual 
impurity specie contained in the substrate. The effect is further compounded by the prevailing substrate temperature regime thereby defining the diffusion length and hence the depth of the boundary layer. This thin film-substrate interface effect is of immense importance in studying the efficiency of electron transport between thin film interfaces of $\mathrm{ZnO}$ based optoelectronic devices.

\section{Conclusions}

In this work, AZO thin films were deposited using MOCVD technique using single solid precursor. The factorial decrease in the $\mathrm{Zn} / \mathrm{Al}$ ratio and the corresponding increase in the $\mathrm{Al}$ dopant concentrations of the AZO thin films play an important role in the properties of the AZO thin films, i.e. in the sheet resistance, morphology, transmittance and energy band gap after the thin films growth.

We have used a range of characterization techniques to study an ensemble of AZO thin films which allowed us to show that $\mathrm{ZnO}$ thin films can be effectively doped under improvable but yet economic processing conditions at relatively low temperature $\left(420^{\circ} \mathrm{C}\right)$. Particularly, $10 \mathrm{~mol} . \%$ AAA AZO thin film exhibited a much promising lower resistivity of $19.88 \Omega$-cm with a corresponding average transmittance of $89 \%$ and $91 \%$ at $\lambda=550 \mathrm{~nm}$. This value of resistivity establishes a remarkable improvement by a factor of 957 over that of the undoped $\mathrm{ZnO}$ and an improvement by a factor of 53 over that of 5 mol.\% AAA. Thus, our results that the doping methodology adopted for deposition of AZO thin films in this work are suitable for potential applications in high performance optoelectronics devices. These results also establish a route to achieve adequately controllable doping efficiency of $\mathrm{ZnO}$ via the incorporation of $\mathrm{Al}$ dopants within its solubility limit.

\section{Conflicts of Interest}

The authors declare no conflicts of interest regarding the publication of this paper.

\section{References}

[1] Minami, T. (2005) Semiconductor Science and Technology, 20, S35-S44. https://doi.org/10.1088/0268-1242/20/4/004

[2] Liu, H., Avrutin, V., Izyumskaya, N., Özgür, Ü. and Morkoç, H. (2010) Superlattices and Microstructures, 48, 458-484. https://doi.org/10.1016/j.spmi.2010.08.011

[3] Ellmer, K. (2010) Nature Photonics, 6, 809-817. https://doi.org/10.1038/nphoton.2012.282

[4] Xue, S.-W. (2012) Physics Procedia, 25, 345-349. https://doi.org/10.1016/j.phpro.2012.03.307

[5] El hamali, S.O., Cranton, W.M., Kalfagiannis, N., Hou, X., Ranson, R. and Koutsogeorgis, D.C. (2016) Optics and Lasers in Engineering, 80, 45-51.

[6] Lin, Y.C., Chen, M.Z., Kuo, C.C. and Yen, W.T. (2009) E Colloids and Surfaces A: Physicochemical and Engineering Aspects, 337, 52-56. 
https://doi.org/10.1016/j.colsurfa.2008.11.049

[7] Wang, X.-J., Lei, Q.-S., Xu, W., Zhou, W.-L. and Yu, J. (2009) Materials Letters, 63, 1371-1373. https://doi.org/10.1016/j.matlet.2008.12.027

[8] Babu, B.J., Maldonado, A., Velumani, S. and Asomoza, R. (2010) Materials Science and Engineering B, 174, 31-37. https://doi.org/10.1016/j.mseb.2010.03.010

[9] Chen, W.-J., Liu, W.-L., Hsieh, S.-H. and Hsu, Y.-G. (2012) Procedia Engineering, 36, 54-61. https://doi.org/10.1016/j.proeng.2012.03.010

[10] Hou, Q., Meng, F. and Sun, J. (2013) Nanoscale Research Letters, 8, 144-151. https://doi.org/10.1186/1556-276X-8-144

[11] Ammaih, Y., Lfakir, A., Hartiti, B., Ridah, A., Thevenin, P. and Siadat, M. (2014) Optical and Quantum Electronics, 46, 229-234.

https://doi.org/10.1007/s11082-013-9757-2

[12] Palimar, S., Banger, K.V. and Shivakumar, G.K. (2012) Journal of Applied Sciences, 12, 1775-1777. https://doi.org/10.3923/jas.2012.1775.1777

[13] Kaur, G., Mitra, A. and Yadav, K.L. (2015) Progress in Natural Science: Materials International, 25, 12-21.

[14] Hopkins, P.D. and Douglas, B.E. (1964) Inorganic Chemistry, 3, 357-360. https://doi.org/10.1021/ic50013a011

[15] Park, K.C., Ma, D.Y. and Kim, K.H. (1997) Thin Solid Films, 305, 201-209. https://doi.org/10.1016/S0040-6090(97)00215-0

[16] Fragala, M.E., Malandrino, G., Giangregorio, M.M., Losurdo, M., Bruno, G., Lettieri, S., Amato, L.S. and Maddalena, P. (2009) Chemical Vapor Deposition, 15, 327-333.

[17] Burstein, E. (1954) Physics Review B, 93, 632-633. https://doi.org/10.1103/PhysRev.93.632

[18] Roth, A.P., Webb, J.B. and Williams, D.F. (1982) Physics Review B, 25, 7836-7839. https://doi.org/10.1103/PhysRevB.25.7836

[19] Tauc, J., Grigorovici, R. and Vancu, A. (1966) Physica Status Solidi (b), 15, 627-637. https://doi.org/10.1002/pssb.19660150224

[20] Roth, A.P., Webb, J.B. and Williams, D.F. (1981) Solid State Communications, 39, 1269-1271. https://doi.org/10.1016/0038-1098(81)90224-6

[21] Srikant, V. and Clarke, D.R. (1997) Journal of Materials Research, 12, 1425-1428. https://doi.org/10.1557/JMR.1997.0193

[22] Walsh, A., Juarez, L.F., Da Silva and Wei, S.-H. (2008) Physical Review B, 78, Article ID: 075211. https://doi.org/10.1103/PhysRevB.78.075211

[23] Reynolds, D.C., Look, D.C. and Jogai, B. (2000) Journal of Applied Physics, 88, 5760-5763. https://doi.org/10.1063/1.1320026

[24] Li, L.N., Zhao, Y., Chen, X.L., Sun, J. and Zhang, X.D. (2012) Physics Procedia, 32, 687-695. https://doi.org/10.1016/j.phpro.2012.03.619

[25] Huang, R., Robl, W., Ceric, H., Detzel, T. and Dehm, G. (2010) IEEE Transactions on Device and Materials Reliability, 10, 47-53. https://doi.org/10.1109/TDMR.2009.2032768

[26] Haacke, G. (1976) Journal of Applied Physics, 47, 4086-4089. https://doi.org/10.1063/1.323240

[27] Moholkar, A.V., Pawar, S.M., Rajpure, K.Y., Bhosale, C.H. and Kim, J.H. (2009) Applied Surface Science, 255, 9358-9364.

https://doi.org/10.1016/j.apsusc.2009.07.035 
[28] Gomez, H., Maldonado, A., Casatanedo-perez, R., Torres-Delgado, G., de La, M. and Olvera, L. (2007) Materials Characterization, 58, 708-714.

https://doi.org/10.1016/j.matchar.2006.11.012

[29] Jayaraman, V.K., Álvarez, A.M., Bizarro, M., Koudriavtsev, Y. and de la Luz Olvera Amador, M. (2017) Thin Solid Films, 642, 14-19.

https://doi.org/10.1016/j.tsf.2017.09.012 